A Bernárdez-Rodal, G Padilla-Castillo (2018): "Mujeres cineastas y mujeres representadas en el cine comercial español (2001-2016)”. Revista Latina de Comunicación Social, 73, pp. 1247 a 1266.

\title{
Mujeres cineastas y mujeres representadas en el cine comercial español (2001-2016)
}

\author{
Female filmmakers and women's representation in \\ Spanish commercial cinema (2001-2016)
}

\begin{abstract}
Asunción Bernárdez-Rodal [CV] C C Departamento de Periodismo y Nuevos Medios. Facultad de Ciencias de la Información. Instituto de Investigaciones Feministas - Universidad Complutense de Madrid (UCM), España - asbernar@ucm.es

Graciela Padilla-Castillo [ $\underline{\mathrm{CV}}]$ G $\mathrm{G}$ Departamento de Periodismo y Nuevos Medios. Facultad de Ciencias de la Información. Instituto de Investigaciones Feministas - Universidad Complutense de Madrid (UCM), España - gracielp@ucm.es
\end{abstract}

\begin{abstract}
s
[ES] Introducción. Se investigan las mujeres en el cine comercial español: directoras y personajes. Metodología. Se estudian fuentes primarias y secundarias; se analizan, de forma cuantitativa y diacrónica, las películas españolas más taquilleras, entre 2001 y 2016; se examinan, de manera cualitativa y descriptiva, protagonistas, tramas y estereotipos, de un corpus de 26 películas. Resultados. El género dominante es la comedia. Hay 36 protagonistas masculinos y 23 femeninos. El grupo gira en torno a los deseos de varones. Discusión. Ellos mueven la acción y son antihéroes, con sentimentalidad infrarrepresentada. Las mujeres son acompañantes, con acciones de cuidados y mediación familiar. Conclusiones. En España, ninguna mujer ha dirigido película que haya recaudado más de 10 millones de euros. La realidad no cambiará mientras no cambie la representación. El cine comercial puede construir ciudadanos cívicos, respetuosos, humanos; y no meros consumidores, que respondan a intereses mercantiles de la industria cinematográfica.

[EN] Introduction. This article analyses the representation of women in Spanish commercial cinema: as film directors and as characters. Methods. The study is based on the analysis of primary and secondary sources; the quantitative and diachronic analysis of the highest-grossing Spanish films from 2001 to 2016; the qualitative and descriptive examination of the protagonists, plots and stereotypes of a sample of 26 films. Results. Comedy is the dominant genre. There are 36 male protagonists and 23 female protagonists. The selected films revolve around the wishes of men. Discussion. Men lead the
\end{abstract}


action, are antiheroes, and their sentimentality is underrepresented. Women are companions of men and are in charge of family caretaking and mediation. Conclusions. In Spain, no woman has directed a film that has grossed more than 10 million euros. This situation will not change until representation changes. Commercial cinema can build civic, respectful and human citizens; and not mere consumers, who respond to the commercial interests of the film industry.

\section{Keywords}

[ES] Mujeres; Cine español; Cine comercial; Representación; Estereotipos de género.

[EN] Women; Spanish cinema; commercial cinema; representation; gender stereotypes.

\section{Contents}

[ES] 1. Introducción. 2. Metodología. 3. Resultados. 4. Discusión. 5. Conclusiones. 6. Referencias bibliográficas.

[EN] 1. Introduction. 2. Methods. 3. Results. 4. Discussion. 5. Conclusions. 6. References.

Traducción de CA Martínez-Arcos

Doctor en Comunicación (Universidad de Londres)

\section{Introducción}

El propósito de esta investigación es estudiar a las mujeres en el cine comercial español, desde dos perspectivas trascendentales: 1) su presencia profesional como directoras, y 2) su representación y estereotipación, positiva o negativa, en las películas. Para conseguir resultados sólidos y profundos, se ha elegido el periodo de quince años, comprendido entre 2001 y 2016.

Este trabajo forma parte de un proyecto mayor, sobre consumo cultural y brechas digitales de este consumo. Como paso imprescindible, parte del equipo investigador ha analizado el cine español, en las pantallas tradicionales, antes de su paso a los dispositivos digitales.

Los dos objetivos de este trabajo visibilizan un problema grave y poco investigado: las mujeres en España están accediendo, de forma generalizada, al trabajo en medios audiovisuales. Sin embargo, les sigue costando ocupar los puestos más relevantes de este tipo de producciones culturales. De acuerdo a CIMA (Asociación de Mujeres Cineastas y Medios Audiovisuales), la presencia laboral de la mujer en el cine español es casi tres veces menor que la del hombre: 26\% frente a 74\% (CIMA, 2017). Según su presidenta, Virginia Yagüe, es "incorrecto el concepto cine de mujeres" porque "no es que las mujeres hagan un tipo de cine”, sino que hacen el que les permite el presupuesto (Bernal-Triviño, 2017).

Para acceder a las ayudas directas del Fondo de Cinematografía hay que ajustarse a los requisitos ministeriales del año anterior. La principal condición es manejar “un presupuesto mínimo de un millón doscientos mil euros” (Bernal-Triviño, 2017). Y “de media, los presupuestos de películas dirigidas por mujeres rondan los ochocientos mil euros, así que, de manera general, no se cumple el requisito" (Bernal-Triviño, 2017).

Aceptamos que no todas las directoras tienen la pretensión de que sus obras sean exhibidas en las salas comerciales. Aunque no podemos dar por bueno el argumento de que el cine dirigido por mujeres deba ser un cine limitado a un público selecto. Eso sería presuponer que las mujeres asumen un gueto laboral o un nicho temático. La creación cinematográfica busca y necesita del público, por mucho que las películas comerciales sean percibidas como textos de calidad intelectual devaluada, en algunos casos. 
Partimos de los presupuestos de los Estudios Culturales (Barker, 1994; O’Sullivan, 1997; Grossberg, 2010; Kellner, 2011; Mattelart, 2011). A partir de los años setenta del siglo pasado, argumentaron que el consumo de productos masivos puede convertirse en signos de identidad para grupos sociales. Estos los re-significan y convierten en símbolos de resistencia cultural (Segarra, Tur \& Del-Pino, 2017; Murciano \& González, 2018; Ortega, Jiménez \& Lavín, 2018).

Por eso es preocupante que las mujeres no lleguen a dirigir películas (Abad-Tejerina, 2001). Uno de los objetivos del feminismo es situar en clave de igualdad a las mujeres en todas las facetas de la vida; entre ellas, las expresiones artísticas. La principal causa de su exclusión en estas producciones se debe a que hacer cine cuesta mucho dinero. Para escribir una novela o un guión no se necesitan, prácticamente, recursos económicos. Hacer cine y llegar al gran público requiere de una gran inversión.

Las mujeres están muy excluidas del acceso al dinero necesario para llevar adelante sus proyectos. También ocupan lugares secundarios en puestos ejecutivos, dentro de las estructuras laborales del cine. La forma en que se ha producido esa exclusión, en la historia de la cinematografía, ha sido estudiada por distintos investigadores (Núñez-Domínguez, 2010; Núñez-Domínguez, 2012; Zecchi, 2013; Zecchi, 2014; Álvarez, González de Garay y Frutos, 2015).

Éstos han analizado lo que ocurrió con las directoras, antes y después del desarrollo de la potente maquinaria del cine de Hollywood, durante la segunda década del siglo XX. De participar activamente en las primeras producciones cinematográficas, pasaron a desaparecer como directoras, productoras, directoras de fotografía o guionistas. Su existencia se centró en ser actrices o estrellas fabricadas por el sistema publicitario del cine norteamericano, que ha sido emulado por las industrias de los países occidentales.

Desde las teorías del cine feminista también se ha reivindicado un cambio en las estructuras de producción cinematográficas. Reproducen modelos industriales verticales, que favorecen a las figuras de autoridad masculinas. El Programa Marco de Investigación e Innovación de la Unión Europea, Horizonte 2020, plantea la necesidad de apoyar las industrias nacionales de cine, televisión y producción editorial. La Comisión Europea ha insistido en el limitado nivel de desarrollo de la industria cinematográfica europea.

El documento European film in the digital era. Bridging cultural diversity and competitiveness, de mayo de 2014, apuntaba al hecho negativo de que en Europa no se consiguen niveles aceptables de audiencia para la mayoría de sus productos audiovisuales respecto, sobre todo, a la industria norteamericana (Commission to the European Parliament, 2014). Explicaba que el problema principal es la diversidad lingüística; una rémora para el mercado globalizado.

En el contexto español se han realizado evaluaciones de la industria cinematográfica nacional (MolláFurió, 2011; Lara, 2012; Medina-Nieto, 2018) y se han propuesto posibles soluciones (Castro-Paz 2007; Pérez-Rufí, 2012; Altabás-Fernández, 2014). Una dificultad comúnmente observada es la dudosa gestión pública de los recursos dedicados al cine, como industria subvencionada (Belinchón, 2015). La Ley 55/2007 vinculaba la concesión de subvenciones al dinero recaudado en taquilla. Un año después, con el estallido de la crisis financiera, se desplomaron las subvenciones.

Para complicar la situación, en el año 2012, el gobierno del Partido Popular subió los impuestos que gravaban algunos espectáculos, como el cine o el teatro. El IVA pasó de un 8 a un 21\%. Algunas personas vieron como aceptable esta subida, porque consideraban que ir al cine no era un gasto básico. Creían que es una mercancía más, que debe competir por conseguir el favor del público en un mercado libre de bienes culturales y artísticos (Spitta, 2013). 
Este planteamiento contradice la idea principal del Horizonte 2020, que afirma que debemos desarrollar y fortalecer nuestras industrias culturales en un mercado globalizado, e intentar librarnos del dominio de las empresas estadounidenses sobre nuestras producciones culturales europeas.

En enero de 2016, entró en vigor una nueva Ley, en la que se determinaba que las subvenciones fueran concedidas, no por criterio de taquilla, sino por la presentación de un proyecto. Este cambio se debió al descubrimiento del fraude de taquilla: se aumentaban las cifras de recaudación de forma sistemática. Siguió sin contentar, porque los criterios de selección favorecían los proyectos de las grandes productoras.

En abril de 2018, se ha sabido que las ayudas para proyectos cinematográficos españoles sólo sumarán un total de 30 millones de euros. Es una cifra muy baja, comparándola con Francia e Italia, donde las mismas ayudas superan, en cada país, los 350 millones de euros. Pese a todo, en España se está viviendo un momento de optimismo respecto a las producciones mediáticas. El Catálogo del Cine Español (Ministerio de Educación, Cultura y Deporte, 2017), muestra un buen ritmo de estrenos, si bien han descendido las pantallas por persona.

Casi todos los mercados europeos están colonizados por la industria cinematográfica norteamericana, integrada en grandes conglomerados de comunicación. En el caso español, las pantallas están controladas por Cinesa, que pertenece a United Cinema Inc. USA; Yelmo, propiedad de CinépolisMéxico; y Kinépolis, una empresa de titularidad belga. La industria del cine español está dominada por capitales extranjeros, en todos sus sectores: producción, distribución y exhibición.

En este contexto, en el que se da un papel importante a la producción de bienes culturales en la economía de un país, fue muy importante el ejemplo del Reino Unido. En 2006, consiguió que su producción cultural fuese un 8\% del Producto Interior Bruto (PIB). Creó un modelo a seguir para los estados europeos (Olite-Aldea, 2015), que se lanzaron a desarrollar una "economía cultural” (Power \& Scott, 2004).

La pregunta es si industrias relativamente pequeñas, como la española, pueden competir con los grandes, como Estados Unidos, India o China. Tal como ha expuesto Martel (2011: 24), los equilibrios de poder en la esfera mundial se mantienen a base de soft power: "La cultura norteamericana está en el corazón mismo de ese poder de influencia tanto si es high como si es low, tanto en el arte como en el entertainment, tanto si se produce en Harvard como si se produce en Hollywood” (Martel, 2011: 10). La cultura mainstream se elabora en grandes conglomerados de producción.

El Instituto de Estadística de la UNESCO (2013) publicó el informe Mercados emergentes y la digitalización de la industria cinematográfica. Decía que la mayoría de las películas que se produce en el mundo están orientadas a un consumo masivo y, sobre todo, al público joven. Los títulos de más éxito, y que consiguen más público, presentan personajes de cómic o son sagas, que van acompañadas de grandes campañas publicitarias (UNESCO, 2013).

Estos grandes éxitos son un atolladero para el despegue de las industrias nacionales, ya que las producciones norteamericanas dominan las listas de las películas más taquilleras en el mundo, año tras año. Prácticamente todas estas cintas son distribuidas por los seis estudios de Hollywood más importantes: CBS Corporation, Comcast Corporation, News Corp., The Walt Disney Company, Time Warner Inc. y Viacom Inc. En este contexto, ¿¿cómo puede sobrevivir una pequeña industria nacional como la española? ¿Cómo pueden trabajar, de forma profesional, las mujeres en una industria altamente masculinizada, como el cine? ¿Tantos directores pueden hacer una representación aceptable de las mujeres en sus personajes femeninos? 
En un estudio impulsado por Women in Film Los Ángeles y Sundance Institute, presentado en 2013, se demostró que existen más mujeres en el cine independiente americano que en el cine comercial de Hollywood. La memoria evaluó la presencia de las mujeres en distintos puestos de responsabilidad, en las películas presentadas al festival de Sundance. Se comprobó que, en estas películas alternativas, la participación femenina estaba en torno al 30\%, superando la media de películas comerciales (Women in Film \& Sundance Institute, 2013).

También se vio que para muchas profesionales era más fácil acceder al cine documental que al cine de ficción, debido a que es más cara la realización de este último. Llegaron a otra conclusión interesante: las directoras tienden a dar más trabajo a otras mujeres detrás de la cámara en puestos de responsabilidad como montadoras o directoras de fotografía, de lo que lo hacen los hombres en los mismos puestos.

Esta investigación recogía conclusiones sobre la percepción de las mujeres sobre su propia discriminación en el entorno laboral cinematográfico, en el que interactúan varios factores. Las barreras financieras asociadas al género representaban un 39,2\%; los estereotipos sexistas de los sets de rodaje, un 17,7\%; la conciliación laboral que sigue recayendo sobre las mujeres, un 19,6\%; y las decisiones de contratación excluyentes, un 13,7\%.

Women in Film Los Angeles (2017) amplió y actualizó el estudio, con datos entre 2007 y 2016. Según los resultados, en las películas estrenadas en ese lapso, las mujeres sólo fueron un $4,2 \%$ de las directoras, un $13,2 \%$ de las guionistas, un $1,7 \%$ de las compositoras musicales y un $20,7 \%$ de las productoras.

En el mercado cinematográfico en España, las mujeres padecen una situación similar a Estados Unidos y al resto de Europa. El avance es verdaderamente lento, aunque no se ha estancado del todo (MartínezCollado \& Navarrete-Tudela, 2011). Si bien se camina pausado (Arranz-Lozano, 2010), es evidente que cada vez acceden más mujeres a la dirección. Y es de esperar que también a otros puestos de responsabilidad en el entorno cinematográfico, que las hagan estar mejor representadas en la gran pantalla.

\section{Metodología}

Para cumplir los objetivos expuestos, analizar la problemática detectada y asegurar rigor y validez científicos, se ha elegido una metodología en tres pasos: 1) Búsqueda y estudio de fuentes primarias (libros, entrevistas y películas) y fuentes secundarias (artículos de investigación, bases de datos e informes sobre cinematografía, internacional y española); 2) Enumeración y análisis, cuantitativo y diacrónico, de las películas españolas más taquilleras, entre 2001 y 2016, que superaron la barrera de los diez millones de euros de recaudación en salas; 3) Examen y reconocimiento, cualitativo y descriptivo, de los y las protagonistas, tramas y estereotipos de los títulos resultantes.

El corpus final consta de 26 películas españolas, dentro de las 100 más taquilleras de la historia del cine español, de acuerdo al informe oficial Largometrajes españoles con mayor número de espectadores y con mayor recaudación (Ministerio de Educación Cultura y Deporte, 2017). Abarcar la cuarta parte del universo total de ese centenar de películas, de toda la historia del cine español, avala que la muestra y las unidades de análisis seleccionadas proporcionan resultados originales, válidos y efectivos.

\section{Resultados}

Distribuimos sinópticamente los hallazgos, de forma escueta, clara y ordenada, en dos tablas de elaboración propia. La primera recoge las 26 películas de producción española, de 2001 a 2016, que 
RLCS, Revista Latina de Comunicación Social, 73 - Páginas 1247 a 1266

[Investigación] [Financiada] DOI: 10.4185/RLCS-2018-1305 | ISSN 1138-5820 | Año 2018

superaron los diez millones de euros de recaudación. Conjuntamente, aparecen el nombre y apellidos del director, la recaudación oficial y exacta en euros, y el género cinematográfico:

Tabla 1: Películas españolas que superaron los 10 millones de euros de recaudación en salas.

\begin{tabular}{|c|c|c|c|c|}
\hline AÑO & TÍTULO & DIRECTOR & $\begin{array}{c}\text { RECAUDACIÓN } \\
\text { EN EUROS }\end{array}$ & GÉNERO \\
\hline 2001 & $\begin{array}{l}\text { 1. Los otros } \\
\text { 2. Torrente 2: Misión en } \\
\text { Marbella }\end{array}$ & $\begin{array}{l}\text { Alejandro Amenábar } \\
\text { Santiago Segura }\end{array}$ & $\begin{array}{l}27.254 .163,38 € \\
22.142 .173,13 €\end{array}$ & $\begin{array}{l}\text { Misterio- } \\
\text { terror } \\
\text { Comedia }\end{array}$ \\
\hline 2002 & 3. El otro lado de la cama & Emilio Martínez-Lázaro & $12.616 .656,38 €$ & Comedia \\
\hline 2003 & $\begin{array}{l}\text { 4. La gran aventura de } \\
\text { Mortadelo y Filemón } \\
\text { 5. Días de fútbol }\end{array}$ & $\begin{array}{l}\text { Javier Fesser } \\
\text { David Serrano de la Peña }\end{array}$ & $\begin{array}{l}22.847 .733,13 € \\
12.212 .123,98 €\end{array}$ & $\begin{array}{l}\text { Comedia } \\
\text { Comedia }\end{array}$ \\
\hline 2004 & 6. Mar adentro & Alejandro Amenábar & $19.837 .472,83 €$ & Drama \\
\hline 2005 & $\begin{array}{l}\text { 7. Torrente 3: El Protector } \\
\text { 8. El reino de los cielos }\end{array}$ & $\begin{array}{l}\text { Santiago Segura } \\
\text { Ridley Scott }\end{array}$ & $\begin{array}{l}18.168 .924,78 € \\
11.984 .458,68 €\end{array}$ & $\begin{array}{l}\text { Comedia } \\
\text { Drama } \\
\text { histórico } \\
\end{array}$ \\
\hline 2006 & $\begin{array}{l}\text { 9. Alatriste } \\
\text { 10. Volver }\end{array}$ & $\begin{array}{l}\text { Agustín Díaz Yanes } \\
\text { Pedro Almodóvar }\end{array}$ & $\begin{array}{l}16.715 .741,56 € \\
10.243 .096,37 €\end{array}$ & $\begin{array}{l}\text { Aventuras } \\
\text { Drama }\end{array}$ \\
\hline 2007 & 11. El Orfanato & Juan Antonio Bayona & $25.061 .449,98 €$ & $\begin{array}{l}\text { Misterio- } \\
\text { terror }\end{array}$ \\
\hline 2008 & & - & - & - \\
\hline 2009 & $\begin{array}{l}\text { 12. Ágora } \\
\text { 13. Celda } 211 \\
\text { 14. Planet } 51\end{array}$ & $\begin{array}{l}\text { Alejandro Amenábar } \\
\text { Daniel Monzón } \\
\text { Jorge Blanco }\end{array}$ & $\begin{array}{l}21.391 .197,61 € \\
13.145 .423,48 € \\
11.682 .316,48 €\end{array}$ & $\begin{array}{l}\text { Drama } \\
\text { histórico } \\
\text { Policiaca } \\
\text { Infantil } \\
\end{array}$ \\
\hline 2010 & & - & - & - \\
\hline 2011 & 15. Torrente 4: Lethal Crisis & Santiago Segura & $19.356 .588,23 €$ & Comedia \\
\hline 2012 & $\begin{array}{l}\text { 16. Lo imposible } \\
\text { 17. Las aventuras de Tadeo } \\
\text { Jones } \\
\text { 18. Tengo ganas de ti }\end{array}$ & $\begin{array}{l}\text { Juan Antonio Bayona } \\
\text { Enrique Gato } \\
\text { Fernando González } \\
\text { Molina }\end{array}$ & $\begin{array}{l}42.408 .546,61 € \\
18.211 .727,53 € \\
12.142 .858,78 €\end{array}$ & $\begin{array}{l}\text { Drama } \\
\text { Infantil }\end{array}$ \\
\hline $2013-$ & & - & - & - \\
\hline 2014 & $\begin{array}{l}\text { 19. Ocho apellidos vascos } \\
\text { 20. El niño } \\
\text { 21. Torrente 5: Operación } \\
\text { Eurovegas }\end{array}$ & $\begin{array}{l}\text { Emilio Martínez-Lázaro } \\
\text { Daniel Monzón } \\
\text { Santiago Segura }\end{array}$ & $\begin{array}{l}55.379 .947,62 € \\
16.206 .693,87 € \\
10.634 .693,53 €\end{array}$ & $\begin{array}{l}\text { Comedia } \\
\text { Policiaca } \\
\text { Comedia }\end{array}$ \\
\hline 2015 & 22. Ocho apellidos catalanes & Emilio Martínez-Lázaro & $35.470 .864,94 €$ & Comedia \\
\hline
\end{tabular}




\begin{tabular}{|l|l|l|l|l|}
\hline \multirow{2}{*}{$\begin{array}{l}\text { 23. Palmeras en la nieve } \\
\text { 24. Atrapa la bandera }\end{array}$} & $\begin{array}{l}\text { Fernando González } \\
\text { Molina }\end{array}$ & Enrique Gato & $17.092 .925,42 €$ & $\begin{array}{l}\text { Drama } \\
\text { histórico }\end{array}$ \\
& 25. Perdiendo el norte & Nacho G. Velilla & $10.994 .006,33 €$ & Infantil \\
\hline 2016 & 26. Un monstruo viene a verme & Juan Antonio Bayona & $26.030 .151,93 €$ & Drama \\
\hline
\end{tabular}

Fuente: Elaboración propia a partir del informe Largometrajes españoles con mayor número de espectadores y con mayor recaudación (Ministerio de Educación Cultura y Deporte, 2017).

Como se especificaba en la Metodología, este corpus constituye la cuarta parte de las 100 películas españolas más taquilleras de la historia. Para encontrar la primera directora, María Ripoll, hay que descender la franja de recaudación de los 10 millones. Ocupa el puesto 37, con la película Ahora o Nunca, que recolectó 8.282.836,99 de euros y fue estrenada el 19 de junio de 2015. Es una comedia romántica, que se desarrolla a partir del complejo entramado de los preparativos de una boda, al modo anglosajón.

Por detrás, todavía dentro de ese centenar de cintas, sólo hay otro título dirigido por una mujer. Es Te doy mis ojos, de Icíar Bollaín, en el puesto 89, con 5.021.082,70 de euros de recaudación, estrenada el 24 de septiembre de 2003. Era un drama valiente, que visibilizaba la violencia doméstica dentro de un matrimonio de clase media.

Aparte de estos dos títulos, no hay ningún otro dirigido o codirigido por una mujer; ni en el centenar histórico de las más taquilleras, ni en los 26 títulos que superaron la recaudación de 10 millones de euros, entre 2001 y 2016. Durante 2008, 2010 y 2013, ninguna película española ingresó más de 10 millones de euros y por eso, aparecen en blanco.

El género dominante es la comedia, con diez títulos; frente a siete dramas, tres de ellos de corte histórico; tres filmes infantiles de animación; dos policíacas; dos de misterio-terror; una romántica y una de aventuras.

Elaboramos otra tabla original, para averiguar el número de personajes protagonistas de cada sexo. Los ordenamos por año, título de la película, actores protagonistas y su personaje, actrices protagonistas y su personaje. La enunciación de esos protagonistas se ha realizado tras visualizar todos los títulos y de acuerdo a las fichas oficiales de las películas en bases de datos, y a los premios otorgados o propuestos para los actores y actrices, en la categoría protagonista o principal. En películas corales, donde todos los personajes ocupaban un metraje similar, se han incluido todos los nombres:

Hay 36 protagonistas masculinos frente a 23 protagonistas femeninas. Cuando vemos estas películas, en muchos casos, la sensación es de protagonismo colectivo: un grupo humano que actúa en torno a una trama.

Sin embargo, esa actividad grupal gira en torno a los deseos de los varones, en la mayoría de los casos. Cumplen esta característica, por ejemplo, Días de fútbol, El reino de los cielos, Celda 211, Ocho apellidos vascos, Ocho apellidos catalanes, Perdiendo el Norte, Tengo ganas de ti, Atrapa la bandera y Las aventuras de Tadeo Jones. La razón de incluir estas dos últimas es que a pesar de que el peso de la narración recae sobre un personaje masculino, son un grupo de niños los que se apoyan y cooperan para resolver los conflictos que se plantean a lo largo de la trama. 
RLCS, Revista Latina de Comunicación Social, 73 - Páginas 1247 a 1266

[Investigación] [Financiada] DOI: 10.4185/RLCS-2018-1305 | ISSN 1138-5820 | Año 2018

Tabla 2: Protagonistas masculinos y femeninos de las películas españolas que superaron los 10 millones de euros de recaudación en salas.

\begin{tabular}{|c|c|c|c|}
\hline AÑO & TULO & $\begin{array}{l}\text { PROTAGONISTA MASCULINO } \\
\text { Y SU PERSONAJE }\end{array}$ & $\begin{array}{l}\text { PROTAGONISTA } \\
\text { FEMENINA Y SU } \\
\text { PERSONAJE }\end{array}$ \\
\hline 2001 & $\begin{array}{l}\text { 1. Los otros } \\
\\
\text { 2. Torrente 2: } \\
\text { Misión en } \\
\text { Marbella }\end{array}$ & Santiago Segura (José Luis Torrente). & $\begin{array}{l}\text { Nicole Kidman (Grace } \\
\text { Stewart). }\end{array}$ \\
\hline 2002 & $\begin{array}{l}\text { 3. El otro lado de la } \\
\text { cama }\end{array}$ & $\begin{array}{l}\text { Ernesto Alterio (Javier), Willy Toledo } \\
\text { (Pedro), Alberto San Juan (Rafa). }\end{array}$ & $\begin{array}{l}\text { Paz Vega (Sonia), Natalia } \\
\text { Verbeke (Paula). }\end{array}$ \\
\hline 2003 & $\begin{array}{l}\text { 4. La gran aventura } \\
\text { de Mortadelo y } \\
\text { Filemón }\end{array}$ & $\begin{array}{l}\text { Pepe Viyuela (Filemón), Benito } \\
\text { Pocino (Mortadelo), Janfri Topera } \\
\text { (Profesor Bacterio). } \\
\text { Ernesto Alterio (Antonio), Alberto } \\
\text { San Juan (Jorge), Fernando Tejero } \\
\text { (Serafín), Roberto Álamo (Ramón). }\end{array}$ & $\begin{array}{l}\text { Natalia Verbeke (Violeta), } \\
\text { Nathalie Poza (Patricia). }\end{array}$ \\
\hline 2004 & 6. Mar adentro & Javier Bardem (Ramón Sampedro). & Belén Rueda (Julia). \\
\hline 2005 & $\begin{array}{l}\text { 7. Torrente 3: El } \\
\text { Protector } \\
\text { 8. El reino de los } \\
\text { cielos }\end{array}$ & $\begin{array}{l}\text { Santiago Segura (José Luis Torrente). } \\
\text { Orlando Bloom (Balian de Ibelin), } \\
\text { Liam Neeson (Godofredo de Ibelin), } \\
\text { Edward Norton (Rey Baldwin). }\end{array}$ & Eva Green (Sibylla). \\
\hline 2006 & $\begin{array}{l}\text { 9. Alatriste } \\
\text { 10. Volver }\end{array}$ & Viggo Mortensen (Diego Alatriste). & $\begin{array}{l}\text { Penélope Cruz (Raimunda), } \\
\text { Carmen Maura (Irene). }\end{array}$ \\
\hline 2007 & 11. El orfanato & 7 & Belén Rueda (Laura). \\
\hline 2008 & & 4 & - \\
\hline 2009 & 12. Ágora & - & $\begin{array}{l}\text { Rachel Weisz (Hipatia de } \\
\text { Alejandría). }\end{array}$ \\
\hline
\end{tabular}


RLCS, Revista Latina de Comunicación Social, 73 - Páginas 1247 a 1266

[Investigación] [Financiada] DOI: 10.4185/RLCS-2018-1305 | ISSN 1138-5820 | Año 2018

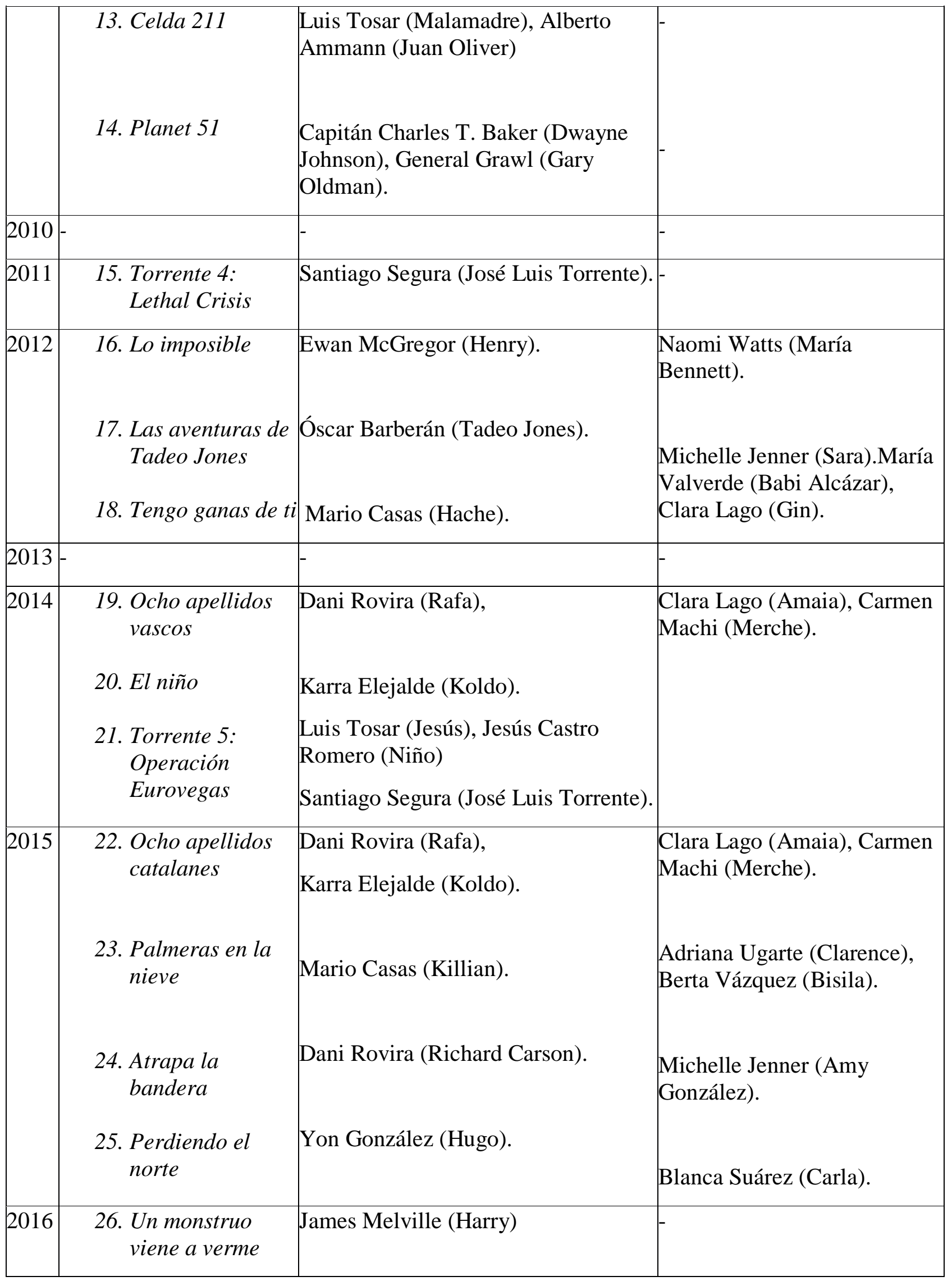


Fuente: Elaboración propia a partir del informe Largometrajes españoles con mayor número de espectadores y con mayor recaudación (Ministerio de Educación Cultura y Deporte, 2017).

Los grandes éxitos de Ocho apellidos vascos y Ocho apellidos catalanes son ejemplares en este sentido. La trama se desarrolla en torno a un joven andaluz que desea conquistar a una mujer vasca, independiente, alejada de sus principios culturales. Los amigos de él y la señora mayor que le acoge como un hijo, Merche, colaboran para que consiga sus fines. En la segunda parte, incluso el suegro, Koldo, pasa de ser un oponente a un ayudante en la estructura narrativa.

Encontramos cuatro veces al personaje de José Luis Torrente, en la franquicia ideada, dirigida, producida y protagonizada por Santiago Segura. Torrente es un verdadero antihéroe que pone en evidencia lo risible, lo ridículo y lo espantoso. Exagera y lleva al límite los supuestos privilegios de su masculinidad. Además, se permite arremeter contra todos los principios de una buena convivencia.

Con los datos, también vemos que al público español le gustan las sagas en las que se recrean los rasgos estereotipados de las autonomías del territorio. A pesar de que ese espíritu es continuamente parodiado y convertido en objeto risible, es interesante pensar si cuestiona o refuerza el sentimiento de unidad. En este caso, las películas de Santiago Segura también son muy significativas. Se trata de obras de humor con un enorme éxito de taquilla, que deconstruyen lo políticamente correcto. No sólo en cuanto al respeto entre distintas nacionalidades, sino también entre culturas, etnias y opciones sexuales. Asimismo, las mujeres aparecen de forma estereotipada y en varias ocasiones, como meros objetos sexuales.

La parodia de las nacionalidades dentro de esta España tan diversa es la base argumental de la ya citada Ocho apellidos vascos, que se ha situado como el film más taquillero de la historia del cine español. Hace un repaso de los estereotipos de la idiosincrasia de vascos y andaluces. En la segunda entrega, Ocho apellidos catalanes, la parodia recae sobre los catalanes de espíritu nacionalista.

Perdiendo el norte también reflexiona sobre la realidad sociológica más actual de España. En clave de comedia toca uno de los principales problemas de la juventud española: la dificultad para encontrar trabajo, a pesar de una alta cualificación. Se trata de una historia de jóvenes forzados a emigrar a otros países, donde su formación académica no es reconocida.

Perdiendo el norte y Tengo ganas de ti son historias que inciden en los problemas y vivencias de los jóvenes actuales, que dejan la adolescencia para hacerse adultos independientes. Sin embargo, tienen un carácter bien distinto. Mientras que en la segunda se cuenta una historia con trasfondo europeo universalista, Perdiendo el norte trata una realidad sociológica española en clave humana y amable: la juventud española, con alta capacitación, tiene que emigrar a Alemania y sobrevive de forma precaria como lo hacían generaciones anteriores.

Precedentemente, Días de fútbol y El otro lado de la cama también hablaron de los problemas de los adultos jóvenes. La situación financiera española y europea era distinta y no se trataba la migración de los jóvenes a Europa, pero sí el paro y el trabajo precario.

En un tiempo más cercano al actual, Perdiendo el norte resuelve, en clave de humor, la tragedia de un país en el que las políticas educativas y de desarrollo no han sido capaces de convertir el mercado de trabajo que responda a las necesidades de las modernas economías del conocimiento. Muestra la realidad de jóvenes altamente cualificados, en un mercado laboral precarizado y un sistema económico más centrado en el turismo y el desarrollo inmobiliario; sin hacer distinciones por género. 
Aparte, hay tres películas de animación que han llevado a hablar del mejor momento histórico de la animación en España, pese a que las dos últimas son dirigidas por el mismo director. Las aventuras de Tadeo Jones y Atrapa la bandera son filmes familiares, que hacen continuas alusiones al modo de hacer películas de aventuras propio del cine norteamericano. En este caso, no existe ninguna referencia formal al cine ni a la cultura española.

\section{Discusión}

El propósito de esta investigación era estudiar a las mujeres en el cine comercial español, desde dos perspectivas: su presencia profesional como directoras, y su representación en las películas. Para conseguir resultados sólidos y profundos, se eligió el periodo de quince años, comprendido entre 2001 y 2016; con un corpus final de 26 películas, donde predominan la comedia y los protagonistas masculinos.

Sobre el primer propósito, no encontramos película dirigida por una mujer, que haya superado los 10 millones de euros de recaudación, en el periodo estudiado de tres lustros. Para encontrar la primera directora, María Ripoll, hay que descender la franja de recaudación de los 10 millones, hasta el puesto 37 de 100. Por detrás, sólo hay otro título dirigido por una mujer, Te doy mis ojos, en el puesto 89, de todas las películas comerciales del cine español.

Resulta complicado valorar el impacto que tienen las películas de mujeres, que han obtenido grandes éxitos en otros circuitos y que no son estrictamente comerciales. Es indudable el reconocimiento internacional, por ejemplo, de la directora Isabel Coixet. No aparece en el corpus, ni en las cien películas más taquilleras del cine español. Sin embargo, ha conseguido introducir varios de sus títulos en circuitos internacionales, con premios y reconocimientos.

El interés que su obra despierta, junto con otras muchas directoras españolas, es incuestionable. Sí lo podemos valorar haciendo una búsqueda de artículos académicos especializados en bases de datos. Isabel Coixet, Iciar Bollaín, Gracia Querejeta, Helena Taberna y un largo etcétera de directoras han encontrado un lugar en la historia de cinematografía española contemporánea

(Heredero, 1998; Zecchi, 2013; Zecchi, 2014; Feenstra, 2014; Zurián, 2015). La mayoría de ellas tiene el valor añadido de no conformarse con elaborar un cine estereotipado y muestran, en sus películas, una búsqueda de lenguaje narrativo propio, si bien algunas no se salen del patrón comercial.

Sobre el segundo propósito, vemos un claro ejemplo de los procesos de desigualdad representativa. Fraser (1997) diría que las desventajas económicas se suman al irrespeto cultural. Las directoras, mujeres reales que tienen que buscar los recursos económicos suficientes para poder rodar, estrenar y distribuir, sufren discriminación frente a los varones.

Esta discriminación se ve reforzada con el hecho de que la feminidad padece de un déficit de representación en esas películas. Hay más protagonistas masculinos que femeninos. Los mecanismos de refuerzo que existen entre las diferencias basadas en el sexo pueden incidir de forma negativa en las construcciones culturales de las diferencias de género. Al respecto, hay numerosas investigaciones interesantes, aplicadas a la prensa (Galarza, Cobo y Esquembre, 2016; Núñez, Arenas y Villar, 2016), a la infancia (Dávila, Revilla y Fernández, 2018) y a las series de televisión (Padilla y Semova, 2009; Padilla, 2010; Padilla, 2012; Padilla, 2014).

Fraser (1997) señaló la importancia de las luchas por la representación digna de los grupos más desfavorecidos y cómo este tipo de lucha ha caracterizado la vida cultural de la posmodernidad. Los grupos históricamente desfavorecidos, tanto en lo económico como en lo representativo, han trabajado por alcanzar un reconocimiento a través de los medios de comunicación. 
Dentro de estas reivindicaciones, las luchas de las mujeres se han concretado en reivindicaciones de igualdad salarial, derecho al control sobre el propio cuerpo o derecho a una representación pública digna. Existe el riesgo de que las luchas por los derechos de las mujeres se banalicen frente a los grandes problemas económicos de todos los estados europeos.

Si aspiramos a la justicia plena, debemos pensar en sus dos dimensiones: la de la redistribución y la del reconocimiento (Fraser, 1997). El concepto de redistribución se refiere a la necesidad de tomar decisiones políticas que distribuyan la riqueza de forma equitativa en el mundo. El reconocimiento tiene que ver con el derecho de los colectivos, de los pueblos o los individuos a ser representados de forma justa en la vida social. La forma de representación puede legitimar las formas de discriminación.

En un trabajo de investigación sobre cine comercial español y violencia de género, que partió de las veinte películas más comerciales estrenadas entre los años 1998 y 2002 (Bernárdez, 2007; Bernárdez, García \& González, 2008), se concluyó que el cine comercial tiende a no representar la violencia física y estructural que padecen las mujeres en la vida real. Sin embargo, si analizamos la forma en que son representadas o ignoradas, se produce violencia como forma de "control social que se ejerce mediante el monopolio de la representación, de las interpretaciones, y en definitiva, de los intercambios simbólicos” (Bernárdez, García y González, 2008: 49).

¿Cómo se lleva a la práctica esa estrategia en textos audiovisuales, aparentemente neutros, como son las películas comerciales que, en principio, se basan en elaborar materiales que gusten a todo el mundo?

En primer lugar, como hemos descrito en el apartado de Resultados, estas películas desarrollan una estrategia narrativa en la que los sujetos desean cosas, mueven la acción y suelen ser hombres. Ellos anhelan determinados objetos o fines. Emprenden acciones, controlan situaciones y conquistan afectivamente a las personas.

Las mujeres son acompañantes o ayudantes que los personajes masculinos tienen para conseguir lo que desean, poniendo así en marcha las estructuras narrativas. En las películas de comedia, aventuras, policíacas o de humor, los varones son los que deciden actuar: buscar un tesoro inca, ir a la luna, conseguir dinero, aunque sea vendiendo droga, detener delincuentes o ir en busca de su enamorada a Euskadi o a Cataluña.

Algunas mujeres, en papeles secundarios, también realizan acciones significativas para la trama. Pero casi siempre, tienen que ver con los cuidados y la mediación, sobre todo, familiar. El personaje de Merche, en los Ocho apellidos vascos y Ocho apellidos catalanes es un ejemplo significativo y cercano. Tiene una personalidad fuerte, aunque su rol es ayudar a los protagonistas masculinos.

Otro ejemplo es la madre en Atrapa la bandera. Este personaje secundario se convierte en la intermediaria entre la rivalidad y el resentimiento que existe entre padre e hijo, los protagonistas. Acaba siendo el centro sentimental de la trama, aunque tenga menos presencia en el filme.

Una excepción admirable es la madre de Lo imposible, un personaje femenino protagonista, cuyo heroísmo está asociado a los cuidados como madre. En una línea similar actúan las protagonistas de Los otros y El orfanato. También son mujeres muy fuertes. Parecen madres excelentes. Madres por encima de todo. Sin embargo, según avanza la trama, su obsesión por la maternidad perfecta las lleva a grandes errores vitales y profundos problemas psicológicos.

En los papeles masculinos, la representación de la sentimentalidad cuenta con más antihéroes que héroes convencionales. Hasta en una película policiaca como El niño, vemos cómo los hombres son capaces de mostrar sus emociones. El problema no es que no tengan sentimientos, sino que son incapaces de mostrarlos o no encajan en su profesión o situación. No es lo que se espera de ellos, en principio. Frente a este modelo, tenemos la masculinidad expuesta en clave de parodia, en los Torrentes 
de Santiago Segura. Como comentábamos, encarna los valores patriarcales más rechazables y caducos. Al respecto, podríamos relacionarlo con investigaciones sobre otros modelos de masculinidad o machos violentos, como los investigados por Caballero-Gálvez y Zurián-Hernández (2016).

Es significativo también el tratamiento del humor de la mayoría de las películas. De acuerdo a los Resultados, la comedia predomina frente al resto de géneros. Muchas de las protagonistas parecen estar permanentemente enfadadas o malhumoradas porque no consiguen que los hombres sean lo que ellas quieren. En Ocho apellidos vascos y Ocho apellidos catalanes vemos esta estrategia representativa. La protagonista principal aparece como alguien con más madurez, en comparación con el resto de personajes; y también como una mujer sin sentido del humor.

Ellos son más simpáticos, casi infantiles y simplones, y consiguen la empatía con los espectadores. El personaje secundario de Merche, la mujer madura en cuanto a edad, de Ocho apellidos vascos y Ocho apellidos catalanes es la excepción: un personaje femenino simpático, sobre todo porque colabora con los hombres (Trimble, 2014) para que ellos consigan sus objetivos.

El uso de la violencia contra las mujeres, como un elemento latente en la sociedad, prácticamente no aparece en las películas analizadas. Sólo en Volver y Tengo ganas de ti. La segunda, y más reciente, es un romance juvenil con una protagonista representada en clave de igualdad, respecto a la fuerza física del hombre con el que inicia una relación; al estilo de las nuevas heroínas de cine que son capaces de pelear y defenderse (Arauna, 2012).

En un momento del metraje, es atacada por dos hombres que la hacen retroceder al lugar simbólico que le corresponde a las mujeres: con un intento de violación del que es rescatada por su enamorado. Este personaje encarna los valores de una heroína fuerte. Se siente empoderada, pero es dibujada también como caprichosa y arbitraria. Cuando conoce al que será su amante, casi sin justificación, le abofetea en un acto incomprensible.

Respondería al antiguo estereotipo de mujer fálica, divulgado en la crítica cinematográfica de los años noventa del siglo pasado. Eran mujeres capaces de ejercer la violencia física, usar las armas y ser agresivas para conseguir sus objetivos. En los últimos años, ese modelo se ha adaptado a personajes que siguen siendo femeninos, cuidan a los demás y pueden ser sentimentales (Bernárdez, 2012). El término resulta poco aceptable para la crítica feminista de cine, ya que implica reconocer que el uso de la fuerza es patrimonio de los varones. Sirve para comprobar cómo el estereotipo de la mujer guerrera ha sido reelaborado por el cine comercial (McCausland, 2017). Ha hecho posible que las guerreras también tengan cualidades propias de los estereotipos femeninos como cuidar a los demás y actuar por motivos que van más allá del entramado amoroso.

Este estereotipo se ha naturalizado, tal vez como resultado sociológico de una generación de jóvenes que ya no se sienten discriminadas. Han sido educadas para el trabajo y la competición y se niegan a ser reconocidas como víctimas. Ya hemos comentado el ejemplo de Tengo ganas de ti, con una protagonista que sale en compañía de una pandilla masculina y aguanta reciamente las bromas y los niveles de alcohol que se les presupone a ellos. Practica el boxeo y tiene un lenguaje y un comportamiento distintos. Todo este empoderamiento desaparece cuando es atacada sexualmente y su enamorado la salve.

Hay personajes de este tipo en otras películas como Las aventuras de Tadeo Jones, en las que se juega a la inversión de papeles convencionales: Tadeo es un perdedor, que encuentra su deseado destino como arqueólogo a base de trompicones y casualidades del destino. Su amiga, Sara, es el personaje fuerte, la Indiana Jones femenina, en versión infantil, sexualizada en su atuendo. 
Ella es perfecta, pero previsible, y colabora para que Tadeo consiga convertirse en el arqueólogo que siempre quiso ser. Es un curioso efecto: a las mujeres se las permite ser activas, dominantes, prácticas y eficaces en sus deseos, siempre que estén en función del proyecto narrativo de sus compañeros.

Otro ejemplo lo encontramos al inicio de El Niño encarnado en una policía fuerte e independiente, incluso deslenguada. Este personaje se acaba diluyendo en la narración, siendo la acompañante del inspector que resuelve el caso. El personaje secundario de la novia marroquí, del mismo filme, es también interesante en este sentido: fuerte, independiente, trapichea con droga para sobrevivir, pero sienta la cabeza y reclama estabilidad a su enamorado a cambio de su amor. Al final de la película, se convierte en el mito de Penélope: capaz de esperar varios años a que su pareja cumpla su condena en la cárcel.

Estas mujeres fuertes tienen un punto extraño en la medida en que incorporan algunos valores de la masculinidad y, al mismo tiempo, se muestran hiperfeminizadas en la forma física. La pregunta es si nos colocan, o no, a las mujeres reales frente a formas simbólicas que de verdad las empoderan. Nuestra respuesta es afirmativa y positiva, en este caso: es interesante que las jóvenes tengan modelos cinematográficos y culturales, en los que puedan reconocerse como fuertes e independientes.

En este punto, creemos que esta investigación abre una vía de trabajo, que ahondaría en estas nuevas heroínas fuertes físicamente e hiperfeminizadas, a la par. Nos interesaría ampliarlo al espectro de súper heroínas de cómic, del universo Marvel y DC, o a personajes femeninos protagonistas en películas convencionales y series de televisión.

El problema es que este fenómeno puede ser leído como un intento de superación de complejo de inferioridad: ellas tienen que ser como los hombres y deben desarrollar sus mismos atributos. La interpretación feminista de estas figuras está en el discurso clásico de Mulvey (1994): son un espectáculo erótico para los hombres. Sin embargo, creemos que no debemos conformarnos con esa mirada estricta. Nos están hablando de nuevas formas de identidad, o de identidades más flexibles en cuanto a la construcción de los géneros.

Otra constatación del análisis llevado a cabo es que la representación de las sexualidades está altamente estereotipada. No existen prácticamente conflictos ni ambigüedades. La heterosexualidad es la norma general en un universo donde apenas aparecen las relaciones homosexuales. Desde luego, este punto abriría otra posible prospectiva de investigaciones.

Tampoco la diversidad cultural es el tema principal de ninguna de las películas, si bien es verdad que aparece como trasfondo de alguna de ellas. A nuestro juicio, las más interesantes son El Niño y Palmeras en la nieve. En la primera, surge una relación amorosa entre el protagonista español y una mujer marroquí. El conflicto no aparece como intercultural, sino como una cuestión que se resuelve a nivel personal y afectivo. Es interesante también Lo imposible, cuyos protagonistas españoles sufren las consecuencias de un tsunami. La población indonesia es una especie de decorado que aumenta el dramatismo de los personajes blancos y occidentales que sufren la tragedia.

Por último, hay un estereotipo original que puede explicarse sólo en un contexto de crisis como el actual: la figura de la madre de Lo imposible. En esta una película de catástrofes, constituye un ejemplo de espectacularización de la capacidad de sufrimiento de las madres por sus hijos. La protagonista es una auténtica mater dolorosa, ensangrentada, herida, magullada, que piensa siempre en los demás, en sus hijos, pero también en los hijos de las otras.

El personaje de María entronca con la tradición de la representación de las mujeres sufrientes. El éxito puede relacionarse con la idea crítica de Badinter (2011: 11) de que la maternidad se ha convertido en el centro del destino femenino. Heroína trágica, mater dolorosa, el conflicto de la película no está en 
el núcleo familiar, sino fuera de él. María sufre una transformación a lo largo de la película. Va de una mujer- madre que ha renunciado a su carrera de médico por cuidar a sus hijos y está pensando en volver a trabajar; a una madre-madre que, luchado contra los efectos de un tsunami, de forma heroica, volviendo a unir a su familia. Al respecto, proponemos el estudio de esas dicotomías en la representación de un mismo personaje, como profesional y como madre.

\section{Conclusiones}

Las mujeres deben estar presentes en todos los ámbitos de la creación cultural, en un momento histórico en el que la cultura se ha convertido en una fuente de recursos económicos importante para los países desarrollados. Sin embargo, su acceso a las producciones cinematográficas de éxito está limitado por la propia industria. Ésta confía más en directores masculinos, a la hora de producir los géneros de mayor comercialización, en este orden: comedias, dramas, policíacas, animación, aventuras.

En España, ninguna mujer ha dirigido película que haya recaudado más de 10 millones de euros. Entre los 100 títulos españoles más taquilleros de la historia, sólo hay dos directoras: María Ripoll, en el puesto 37, e Icíar Bollaín, en el puesto 89. Esta situación requiere de la intervención de los poderes públicos a la hora de realizar las subvenciones al cine. Porque hasta ahora, premia la asistencia de público a las salas, obviando que los públicos se educan culturalmente en la medida en que consumen productos culturales relacionados con el cine, como puede ser la televisión, la música o la literatura. No conseguiremos elevar la calidad de las producciones sin un público educado desde los centros de formación institucionalizados.

El éxito de público no es una garantía de calidad, pero tampoco creemos que los criterios de calidad y público sean excluyentes. Los públicos también se educan en una sensibilidad determinada en la medida en que consumen productos culturales.

Es un hecho que el cine, aun en su estereotipación, ha dado también visibilidad a algunas minorías. Ha teatralizado la posibilidad de mantener un diálogo social entre las personas que ostentan un discurso dominante, y aquellos que representan a ciertas minorías. Muestra lo que todo el mundo piensa y lo que piensan los disidentes a los modelos sexuales, familiares y emocionales.

La exclusión de las mujeres de la producción y la dirección de películas se explica también porque el cine refuerza su invisibilidad simbólica en la representación. Una de las estrategias es la de no hacerlas protagonistas de las historias que se cuentan, ubicándolas como acompañantes o asistentes de los deseos de los hombres. Además, los personajes femeninos sufren un déficit de representación porque poseen caracteres malhumorados y poco simpáticos; y se las atribuyen los valores de género más tradicionales, de cuidadoras, madres, luchadoras.

La realidad no cambiará mientras no cambie la representación. Y la representación no se alterará mientras no surjan nuevas posibilidades de ser en la vida social. En el bucle que se produce entre realidad y ficción está el nudo de género que debemos cambiar para que la sociedad sea más justa con las mujeres, tanto en lo económico como en lo representativo. Porque el cine comercial, como todas las industrias culturales, puede contribuir positivamente a construir ciudadanos cívicos, respetuosos, humanos; y no meros consumidores, que paguen una entrada, llenen las salas y respondan a intereses mercantiles o empresariales de la industria cinematográfica, sin llevarse ningún mensaje de los filmes.

* Investigación financiada. Este artículo es producto de un Proyecto Banco SantanderUniversidad Complutense de Madrid, titulado "Brecha digital entre docentes y estudiantes universitarios: Producción y consumo cultural a través de las redes sociales (Facebook, 
Instagram y Twitter)”, referencia PR41/17-20959, duración 23/11/2017-23/11/2018, dirigido por la Profesora Titular de la UCM Dra. Asunción Bernárdez Rodal.

Fechas:

- inicio de la investigación: 8 de diciembre de 2017.

- término de la investigación: 30 de abril de 2018.

\section{Referencias bibliográficas}

Abad-Tejerina, M.J. (2001): “¿Para qué sirve el cine comercial en la aldea global? La India un caso singular”. Arte, Individuo y Sociedad, 13, pp. 159 a 170.

http://revistas.ucm.es/index.php/ARIS/article/view/ARIS0101110159A/5911

Altabás-Fernández, C. (2014): “Autofinanciación y crowdfunding: Nuevas vías de producción, distribución y exhibición del cine español independiente tras la crisis financiera española”. Historia y Comunicación Social, 19, pp. 387 a 399.

http://revistas.ucm.es/index.php/HICS/article/view/45141/42504

DOI: http://dx.doi.org/10.5209/rev_HICS.2014.v19.45141

Álvarez-Hernández, C., González de Garay-Domínguez, B. y Frutos-Esteban, F.J. (2015):

“Representación de género. Las películas españolas contemporáneas de adolescentes (2009-2014)”. Revista Latina de Comunicación Social, 70, pp. 934 a 960.

http://www.revistalatinacs.org/070/paper/1079/49es.html

DOI: 10.4185/RLCS-2015-1079

Arauna, N. (2012): "Gender violence and the representation of sexual and affective relationships: Reflections on cross-media research”. Catalan Journal of Communication \& Cultural Studies, 4(2), pp. 239 a 248.

http://www.ingentaconnect.com/contentone/intellect/cjcs/2012/00000004/00000002/art00007?crawle $\mathrm{r}=$ true

DOI: https://doi.org/10.1386/cjcs.4.2.239_1

Arranz-Lozano, F. (Ed.) (2010): Cine y género en España: Una investigación empírica. Madrid: Cátedra.

Badinter, E. (2011): La mujer y la madre: un libro polémico sobre la maternidad como nueva forma de esclavitud. Madrid: La Esfera de Libros.

Barker, M. (1994): Introducción a los estudios culturales. Barcelona: Bosch.

Belinchón, B. (2015): “Historia de una subvención. Un repaso a las diversas leyes del Cine que han regulado las ayudas a la producción de películas durante de la democracia”. El País, 24 de noviembre, España: https://elpais.com/cultura/2015/11/23/actualidad/1448293938_944030.html (8 de abril de 2018).

Bernal-Triviño, A.I. (2017): “El techo de cristal de las mujeres en el cine español”. Público, 29 de marzo, España:

http://www.publico.es/culturas/techo-cristal-mujeres-cine-espanol.html (8 de abril de 2018). 
Bernárdez-Rodal, A. (2007): "Representaciones cinematográficas de la violencia de género: Femenino y masculino en el cine comercial español”. Circunstancia, 12, pp. 1 a 12.

Bernárdez-Rodal, A. (2012): “Modelos de mujeres fálicas del postfeminismo mediático: Una aproximación a Millenium, Avatar y Los juegos del hambre”. Anàlisi, 47, pp. 91 a 112.

Bernárdez, A., García, I. y González, S. (2008): Violencia de género en el cine español: Análisis de los años 1998 a 2002 y guía didáctica. Madrid: Editorial Complutense.

Caballero-Gálvez, A.A. y Zurián-Hernández, F.A. (2016): “Machos violentos y peligrosos. La figura del maltratador en el cine almodovariano”. Revista Latina de Comunicación Social, 71, pp. 853 a 873.

http://www.revistalatinacs.org/071/paper/1124/44es.html

DOI: $10.4185 / R L C S-2016-1124$

Castro-Paz, J.L. (2007): “La encrucijada de la historia del cine español”. Comunicar, 15(29), pp. 39 a 45.

https://www.revistacomunicar.com/index.php?contenido=detalles\&numero=29\&articulo=29-2007$\underline{07}$

CIMA (Asociación de Mujeres Cineastas y Medios Audiovisuales) (2017): Informe CIMA 2016. La representatividad de las mujeres en el sector cinematográfico español. Madrid, España: CIMA. https://cimamujerescineastas.es/wp-content/uploads/2018/01/INFORME-FINAL-ESTUDIO2016.pdf (8 de abril de 2018).

Commission to the European Parliament (2014): "European film in the digital era. Bridging cultural diversity and competitiveness". Bruselas, Bélgica: European Parliament.

https://eur-lex.europa.eu/legal-content/EN/TXT/?uri=celex\%3A52014DC0272 (8 de abril de 2018).

Dávila-de-León, M.C., Revilla-Castro, J.C. y Fernández-Villanueva, C. (2018): “Más allá de la mera exposición: Violencia en televisión en horario protegido”. Revista Latina de Comunicación Social, 73, pp. 352 a 368.

http://www.revistalatinacs.org/073paper/1259/18es.html

DOI: $10.4185 / R L C S-2018-1259$

Feenstra, P. (2014): Directoras de cine en España y América latina: Nuevas voces y miradas. Frankfurt: Peter Lang.

Fraser, N. (1997): Iustitia interrupta: reflexiones críticas desde la posición postcolonialista. Santa Fe de Bogotá: Siglo del Hombre Editores.

Galarza-Fernández, E., Cobo-Bedía, R. y Esquembre Cerdá, M. (2016): “Medios y violencia simbólica contra las mujeres”. Revista Latina de Comunicación Social, 71, pp. 818 a 832. http://www.revistalatinacs.org/071/paper/1122/42es.html

DOI: 10.4185/RLCS-2016-1122

Grossberg, L. (2010): Estudios culturales: Teoría, política y práctica. Valencia: Letra Capital. Heredero, C.F. (1998): La mitad del cielo: Directoras españolas de los años 90. Málaga: Primer Festival de Cine Español de Málaga.

Kellner, D. (2011): Cultura mediática: Estudios culturales, identidad y política entre lo moderno y lo posmoderno. Madrid: Akal. 
Lara, F. (2012): Cine español. El estado de la cuestión. Madrid: Academia del Cine.

Martínez-Collado, A. y Navarrete-Tudela, A. (2011): “Mujeres e (industria) audiovisual hoy: Involución, experimentación y nuevos modelos narrativos”. Tesi, 12(1), pp. 8 a 23.

Mattelart, A. (2011): Introducción a los estudios culturales. Barcelona: Paidós.

McCausland, E. (2017): Wonderwoman. El feminismo como superpoder. Madrid: Errata Naturae.

Medina-Nieto, M. (2018): “Análisis crítico de la producción de contenidos y de la ley de la radio y la televisión de titularidad estatal. El caso de TVE”. Revista Latina de Comunicación Social, 73, pp. 730 a 747. http://www.revistalatinacs.org/073paper/1279/38es.html

DOI: $\underline{10.4185 / R L C S-2018-1279}$

Ministerio de Educación, Cultura y Deporte (2017): Catálogo del Cine Español. Madrid, España: Ministerio de Educación, Cultura y Deporte.

http://www.mecd.gob.es/catalogodecine/2015/presentacion.html (8 de abril de 2018).

Ministerio de Educación, Cultura y Deporte (2017): Largometrajes españoles con mayor número de espectadores y con mayor recaudación. Madrid, España: Ministerio de Educación, Cultura y Deporte.

http://www.mecd.gob.es/dam/jcr:bbb653ce-d129-43dc-9d9e-c2d911626c87/33-largos-esp-recesp.pdf (8 de abril de 2018).

Mollá-Furió, D. (2011): “Cine, mercado y publicidad: La industria cinematográfica española y los nuevos modelos de producción”, en Actas del IV Congreso Internacional sobre análisis fílmico, nuevas tendencias e hibridaciones de los discursos audiovisuales en la cultura digital contemporánea (Coord. Por I. Bort, I. García y S. Marta). Madrid: Ediciones de las Ciencias Sociales.

Mulvey, L. (1994): Placer visual y cine narrativo. Miami: Episteme.

Murciano-Martínez, M. y González-Saavedra, C. (2018): “Las industrias culturales y creativas en las comunidades autónomas españolas: El caso Cataluña”. Revista Latina de Comunicación Social, 73, pp. 146 a 167.

http://www.revistalatinacs.org/073paper/1250/09es.html

DOI: $\underline{10.4185 / R L C S-2018-1250}$

Núñez-Domínguez, T. (2010): “Mujeres directoras de cine: Un reto, una esperanza”. Pixel-Bit. Revista De Medios y Educación, 37, pp. 121 a 133.

Núñez Domínguez, T. (2012): Directoras de cine español: Ayer, hoy y mañana, mostrando talentos. Sevilla: Fundación Audiovisual de Andalucía y Universidad de Sevilla.

Ortega-Mohedano, F., Jiménez-Sánchez, A. y Lavín, J.M. (2018): “Industrias culturales y composición de los personajes en las series de animación infantil emitidas en España”. Revista Latina de Comunicación Social, 73, pp. 74 a 88.

http://www.revistalatinacs.org/073paper/1246/05es.html

DOI: $10.4185 / R L C S-2018-1246$

O'Sullivan, T. (1997): Conceptos clave en comunicación y estudios culturales. Buenos Aires: Amorrortu. 
Padilla-Castillo, G. y Semova, D.J. (2009): Los juegos de las series favoritas de los universitarios madrileños. CIC: Cuadernos de información y comunicación, 14, pp. 199 a 211.

Padilla-Castillo, G. (2010): “Los antihéroes televisivos desde las perspectivas del Análisis Transaccional, la Ética, la Moral y la Política”. Revista de análisis transaccional y psicología humanista, 62, pp. 81-101.

Padilla-Castillo, G. (2012): "Las series de televisión sobre médicos como ejemplo de enseñanza en nutrición y gastronomía”. Revista Latina de Comunicación Social, 67, pp. 229 a 247.

http://www.revistalatinacs.org/067/art/954_Complutense/10_Graciela.html

DOI: 10.4185/RLCS-067-954-229-247

Padilla-Castillo, G. (2014): “Teoría de la información y de la comunicación en una serie de televisión: Scandal”. Historia y comunicación social, 19(2), pp. 133-144.

Pérez-Rufí, J. (2012): “La tormenta perfecta del cine español: situación de la industria cinematográfica en España”. Razón y Palabra, 81, pp. 1 a 32.

http://www.razonypalabra.org.mx/N/N81/V81/30_Perez_V81.pdf

Power, D. \& Scott, A.J. (2004): Cultural Industries and The Production of Cultura. New York: Routledge.

Spitta, S. (2013): “Hispanic cinema and the aesthetics of deceleration: Festival report”. Studies in Spanish \& Latin American Cinemas, 10(2), pp. 225 a 234.

http://www.ingentaconnect.com/content/intellect/sslac/2013/00000010/00000002/art00008

DOI: https://doi.org/10.1386/slac.10.2.225_7

Trimble, L. (2014): “Melodrama and gendered mediation”. Feminist Media Studies, 14(4), pp. 663 a 678.

https://www.tandfonline.com/doi/abs/10.1080/14680777.2013.826268?journalCode=rfms20

DOI: https://doi.org/10.1080/14680777.2013.826268

UNESCO (2013): Mercados emergentes y la digitalización de la industria cinematográfica: análisis de la encuesta internacional del UIS del año 2012 sobre las estadísticas de largometrajes. Nueva York: UNESDOC.

http://unesdoc.unesco.org/Ulis/cgi-bin/ulis.pl?catno=227279\&gp=\&lin=1\&ll=f (8 de abril de 2018).

Zecchi, B. (Coord.) (2013): Gynocine: Teoría de género, filmología y praxis cinematográfica. Zaragoza: Amherst.

Zecchi, B. (2014): Desenfocadas: Cineastas españolas y discursos de género. Barcelona: Prensa de la Universidad de Zaragoza.

Zurián, F.A. (Coord.) (2015): Construyendo su propia mirada. Mujeres directoras en el cine español. Madrid: Síntesis.

Women in Film \& Sundance Institute (2013): Inequality for female directors. Los Angeles, Estados Unidos: Women in Film.

https://womeninfilm.org/ffi// (8 de abril de 2018).

Women in Film Los Angeles (2017): Women across popular films from 2007-2016. Los Angeles, Estados Unidos: Women in Film. 
RLCS, Revista Latina de Comunicación Social, 73 - Páginas 1247 a 1266

[Investigación] [Financiada] DOI: 10.4185/RLCS-2018-1305 | ISSN 1138-5820 | Año 2018

https://womeninfilm.org/ (8 de abril de 2018).

\section{Cómo citar este artículo / Referencia normalizada}

A Bernárdez-Rodal, G Padilla-Castillo (2018): "Mujeres cineastas y mujeres representadas en el cine comercial español (2001-2016)”. Revista Latina de Comunicación Social, 73, pp. 1247 a 1266.

http://www.revistalatinacs.org/073paper/1305/64es.html

DOI: $\underline{10.4185 / R L C S-2018-1305}$

- En el interior de un texto:

...A Bernárdez-Rodal, G Padilla-Castillo (2018: 1247 a 1266) ...

O

...A Bernárdez-Rodal et al, 2018 (1247 a 1266) ...

Artículo recibido el 22 de mayo de 2018. Aceptado el 27 de junio.

Publicado el 6 de julio de 2018 